\title{
Role of anti-EA-(D) IgM and anti-EA-(D) IgG tests in patients with primary EBV infection, lymphomas and immunosuppression
}

\author{
Tsvetelina Kostadinova ${ }^{1}$, Liliya Ivanova ${ }^{2,3}$, Tatina Todorova ${ }^{4}$, Zhivka \\ Stoykova $^{2,3}$, Denitsa Tsaneva ${ }^{2}$, Gabriela Tsankova $^{4}$ \\ 1) Section Medical Lab Technicians, Medical College, Medical University, \\ Varna, Bulgaria. \\ 2) Department of Microbiology and Virology, Faculty of Medicine, Medical \\ University, Varna, Bulgaria. \\ 3) Laboratory of Clinical Virology, University Hospital St. Marina, Varna, \\ Bulgaria \\ 4) Department of Preclinical and Clinical Sciences, Faculty of Pharmacy, \\ Medical University, Varna, Bulgaria.
}

\begin{abstract}
Purpose: The EA (early antigen) is expressed during the lytic phase of the EBV life cycle, together with VCA (viral capsid antigen) and MA (membrane antigen). Antibodies to EA (D) IgG occur in the course of primary infection, but not in all patients. The titers increase in the first 3-4 weeks and usually last about 3-4 months. Their presence is also associated with reactivation of the infection due to impaired immune control of the viral replication. The aim of this study was to compare the primary immune response against the major antigens (VCA) and EA (D) in patients with clinically proven primary infection and to define the antibody response to the EA (D) antigen as a marker for reactivation in patients at risk.

Materials/Methods: We examined 86 persons with lymphomas, incl. Hodgkin's lymphoma and non-Hodgkin's lymphoma, immunosuppressed patients, mainly with AML (acute myeloid leukemia) and primary infection (infectious mononucleosis, IM) patients. We used an indirect ELISA for anti-EA (D) IgM/IgG and anti-VCA IgM/IgG (Euroimmun, Germany).

Results: Patients with anti-EA(D) IgM were $29.1 \%$ (95\% CI:19.8\% - 39.9\%, n=25) while patients with àntiEA(D) IgG were $23.3 \%$ (95\% CI:14.8\%-33.6\%, n=20) ( $p>0.05)$. As expected, younger individuals with IM diagnosis predominated among the positive patients. We found isolated ànti-EA(D) IgM in four persons (with lymphoma and immunosuppression) and isolated ànti-EA(D) $\mathrm{IgG}$ in five patients.

Conclusion: The routine diagnostic tests used to detect antibodies to VCA have a much better diagnostic value in defining a primary infection. Use of antibodies against EA (D) in case of isolated anti-VCA IgM and anti-VCA IgG needs further evaluation. Use of anti-EA (D) IgG as a reactivation marker should be compared with Real-time PCR results.
\end{abstract}

Keywords: Epstein-Barr virus, anti-EA(D) $\operatorname{IgM} / \operatorname{IgG}$, anti-VCA $\mathrm{IgM} / \mathrm{IgG}$, infectious mononucleosis, lymphomas, immunosuppression,

\section{INTRODUCTION}

The EA (early antigen) is expressed during the lytic phase of the EBV life cycle, together with VCA (viral capsid antigen) and MA (membrane antigen). It consists of two components - D (diffuse) and R (restricted). Differences are defined by their cell distribution and sensitivity to proteolytic enzymes. According to various studies, antibodies against these components are found in number of EBV-associated diseases. Patients with infectious mononucleosis (IM) and nasopharyngeal carcinoma (NPC) have been shown to have elevated titers mainly against the EA (D) component, whereas patients with Burkitt's lymphoma against the EA (R) component [1]. High levels of anti EA $\mathrm{IgG}$ are detected in chronic active EBV infection.

Only three parameters are accepted as essential for EBV diagnosis in immunocompetent individuals: evidence of anti-VCA IgM, anti-VCA IgG and anti-EBNA1 IgG [2]. Primary infections display positive anti-VCA IgM and IgG, whereas antibodies against EBNA1 are usually not detected. Anti-EBNA1 IgG appear in the end of the primary infection and can differentiate between the primary and the past infection, as different variations in the VCA immune response exist. VCA antibodies persist during the whole life, but can decrease and disappear under immunosuppression. In addition, some individuals may not produce àntiEBNA1 IgG [3]. Antibodies to EA (D) IgG occur in the course of primary infection, but not in all patients. The titers increase in the first 3-4 weeks and usually last for about 3-4 months. In 20-30\% of healthy carriers, they may persist for longer. Their presence is also associated with reactivation of the infection due to impaired immune control of the viral replication [1].

The aim of this study was to compare the primary 
immune response against the major antigens (VCA) and EA (D) in patients with clinically proven primary infection and to define the antibody response to the EA (D) antigen as a marker for reactivation in patients at risk.

\section{MATERIALS AND METHODS}

The leading criterion for patients' selection was the clinical diagnosis. Their serological status was defined only on the basis of anti VCA $\operatorname{IgM} / \mathrm{IgG}$, as only these antibodies are routinely tested in Bulgaria. We examined 86 patients, 28 of whom with lymphomas (Hodgkin's lymphoma (HL) and non-Hodgkin's lymphoma (NHL)), 31 immunosuppressed patients, mainly AML (acute myeloid leukemia) and 27 with IM (infectious mononucleosis).

We used indirect ELISA for anti-EA (D) $\operatorname{IgM} / \operatorname{IgG}$ and anti-VCA IgM/IgG. When calculating the IgM results, the semiquantitative method was applied: Ratio $=$ Extinction of the sample/Extinction of calibrator. Positive samples had a ratio $>1.1$; negative samples had a ratio of $<0.8$. Samples between 0.8 and 1.1 were considered borderline. For IgG, we used the quantitative method for defining positive and negative samples by constructing a calibration curve (Cal 1=200 RU/ml, Cal 2=20 RU/ml, Cal 3=2 RU/ml). Positive results were $>=22 \mathrm{RU} / \mathrm{ml}$; negative samples $<16 \mathrm{RU} / \mathrm{ml}$; and borderline were between 16 and $22 \mathrm{RU} / \mathrm{ml}$.

To determine the means, confidence intervals and Chi-square test of independence, the results were processed with SPSS vs 23.

\section{RESULTS}

The mean age of all individuals was 36.7 (SD \pm 22.6), divided into eight age groups (Figure 1). The highest proportion of included patients was in the groups 1-10 years and 11-20 years. Patients with a clinical diagnosis of IM dominated, followed by immunosuppressed patients (Figure 1).

Fig. 1. Distribution of patients in anti-EA (D) $\operatorname{IgM} / \mathrm{IgG}$ tests according to the clinical diagnosis and the age range.

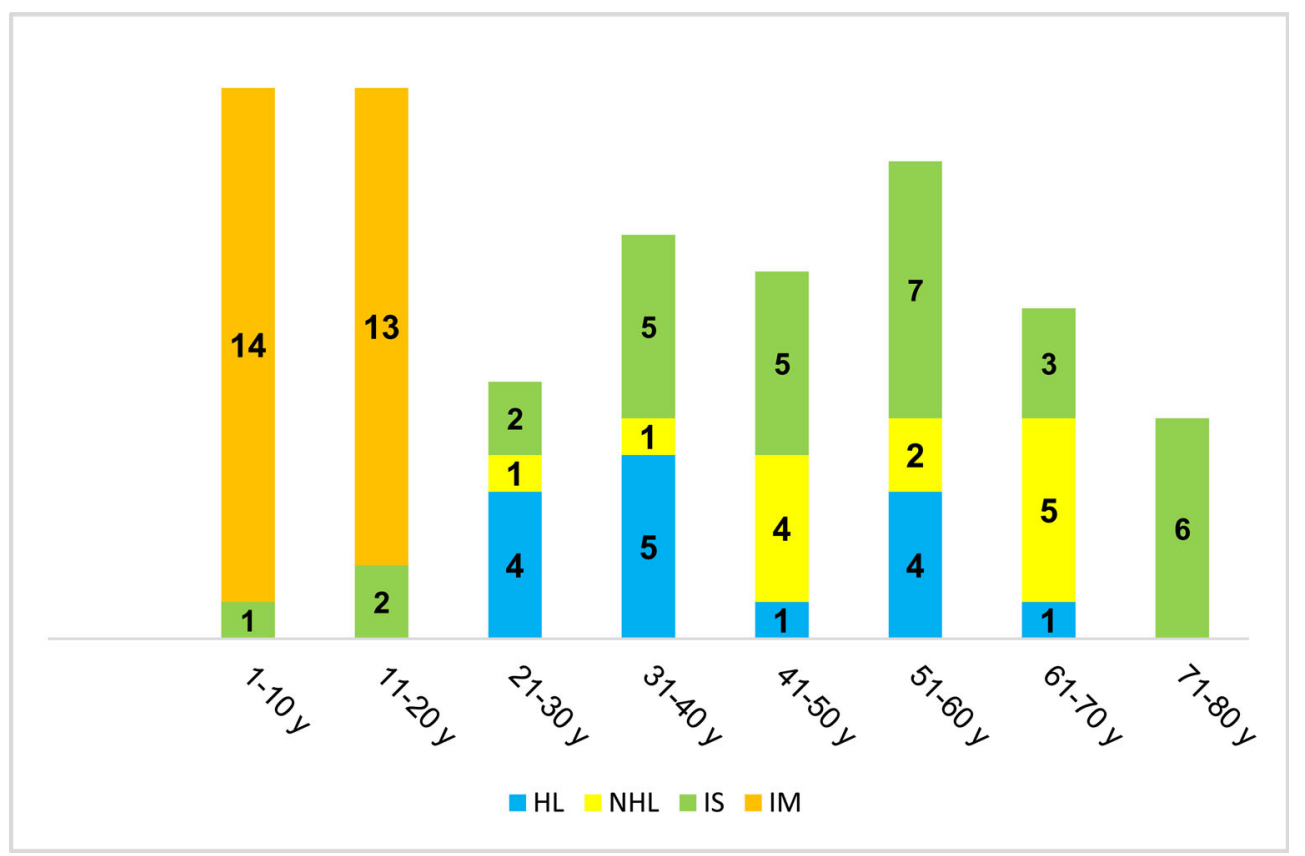

All immunosuppressed patients and those with lymphomas were positive in the anti-VCA IgG assay, and one patient with HL was also positive in anti-VCA IgM. The majority of patients with IM - 88.9\% (95\% CI: $70.8 \%$ $97.6 \%)$ was positive for anti-VCA $\operatorname{IgM}$ and $92.6 \%(95 \%$ CI: $77.7 \%-99.1 \%$ ) for anti-VCA IgG.

Anti-EA (D) IgM positive were $29.1 \%$ (95\% CI: $19.8 \%-39.9 \%, \mathrm{n}=25)$ of all the patients studied. The mean age of positive patients was $17.0(\mathrm{SD} \pm 15.3)$ and was significantly lower than that of the negative patients -45.7 $(\mathrm{SD} \pm 20.0)(\mathrm{p}<0.05)$. The proportion of the positive outcomes was highest among patients in the first age groups in whom IM cases were recorded. This proves that these antibodies are found mainly in primary infection. In older age groups, IgM positive patients were in the age range 41-50 years and 51-60 years. In four of the groups, we did not find positive results.

Anti-EA (D) IgG was found in $23.3 \%$ (95\% CI: $14.8 \%-33.6 \%, \mathrm{n}=20$ ) of the patients studied. Again, the highest proportion of positive subjects was within the first age groups, including patients with IM. Antibodies against the EA of both classes were, therefore, most common in primary infection. We found a higher proportion - $22.2 \%(95 \%$ CI: $2.8 \%-60 \%$ ) of IgG positive individuals in the age group $61-70$ years and $16.7 \%$ (95\% CI: $0.4 \%-64.1 \%$ )at 71-80 years. In the first two age groups, IgM antibodies were of significant prevalence (Figure 2). 
Fig. 2. Distribution of positive patients in anti-EA (D) $\operatorname{IgM} / \operatorname{IgG}$ assays according to the age.

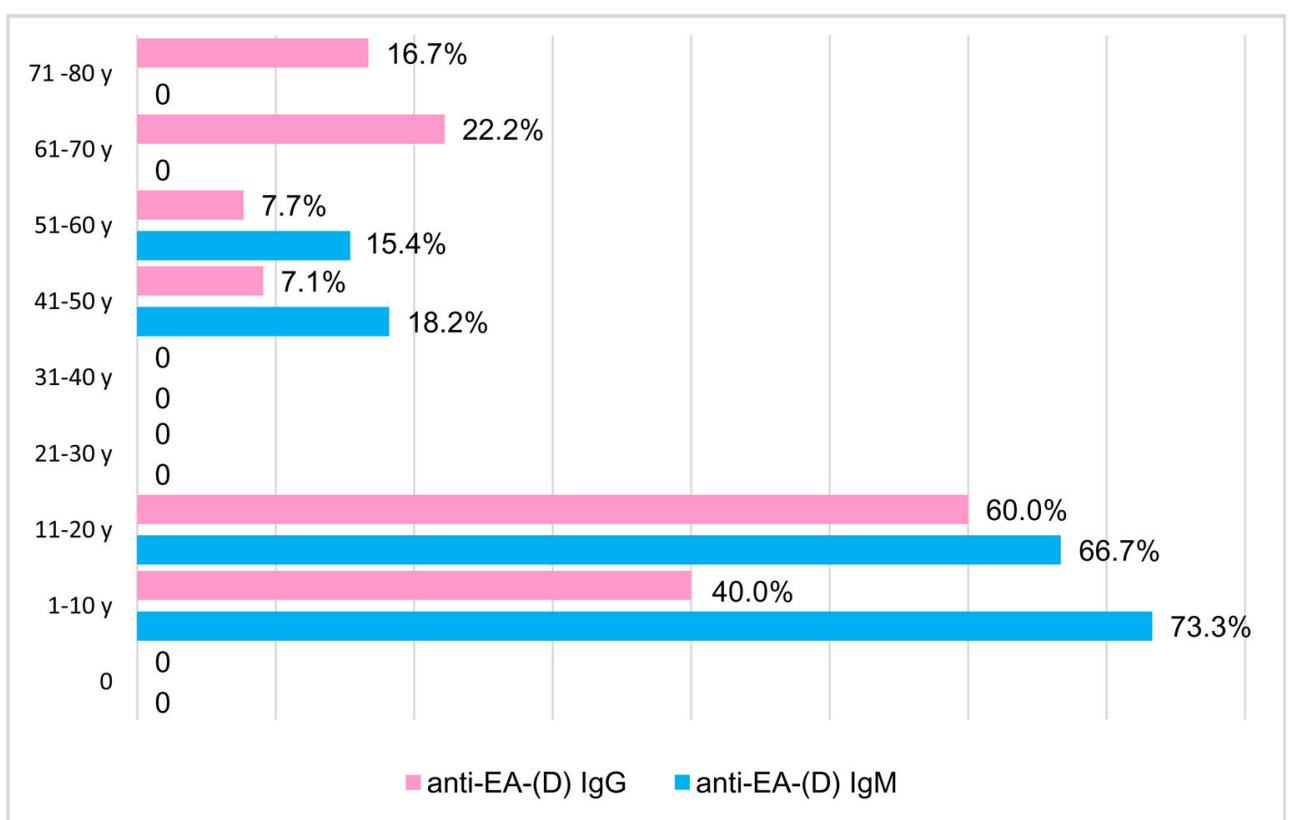

The comparative analysis of the results according to the clinical diagnosis showed the highest proportion of patients positive for the two classes of antibodies to be among those diagnosed with IM. In patients with different

types of lymphomas, anti-EA (D) IgM positive were the more common result, whereas in IS the positive results in the anti-EA (D) IgG test predominated. The difference was not statistically significant ( $\mathrm{p}>0.05)$ (Figure 3).

Fig. 3. Distribution of positive patients in anti-EA (D) $\mathrm{IgM} / \mathrm{IgG}$ assays according to the clinical diagnosis.

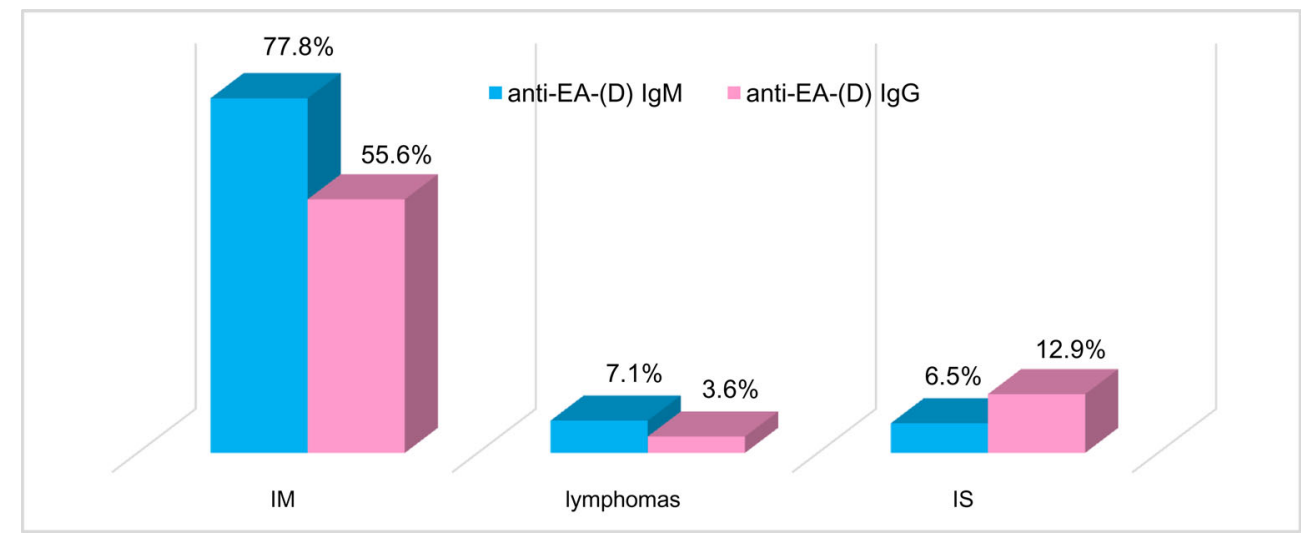

The comparative analysis of the proportion of positive patients with IgM class antibodies against the two viral antigens (VCA and EA-D) showed the same results. Inconsistent results were obtained in four patients. In three patients with IM and one with HL, we demonstrated positivity only in the anti-VCA IgM, whereas in two IS patients and two with different types of lymphomas positivity only in the anti-EA (D) IgM (Figure 4). 
Fig. 4. Distribution of positive patients in anti-EA (D) IgM/IgG and anti-VCA IgM/IgG assays.

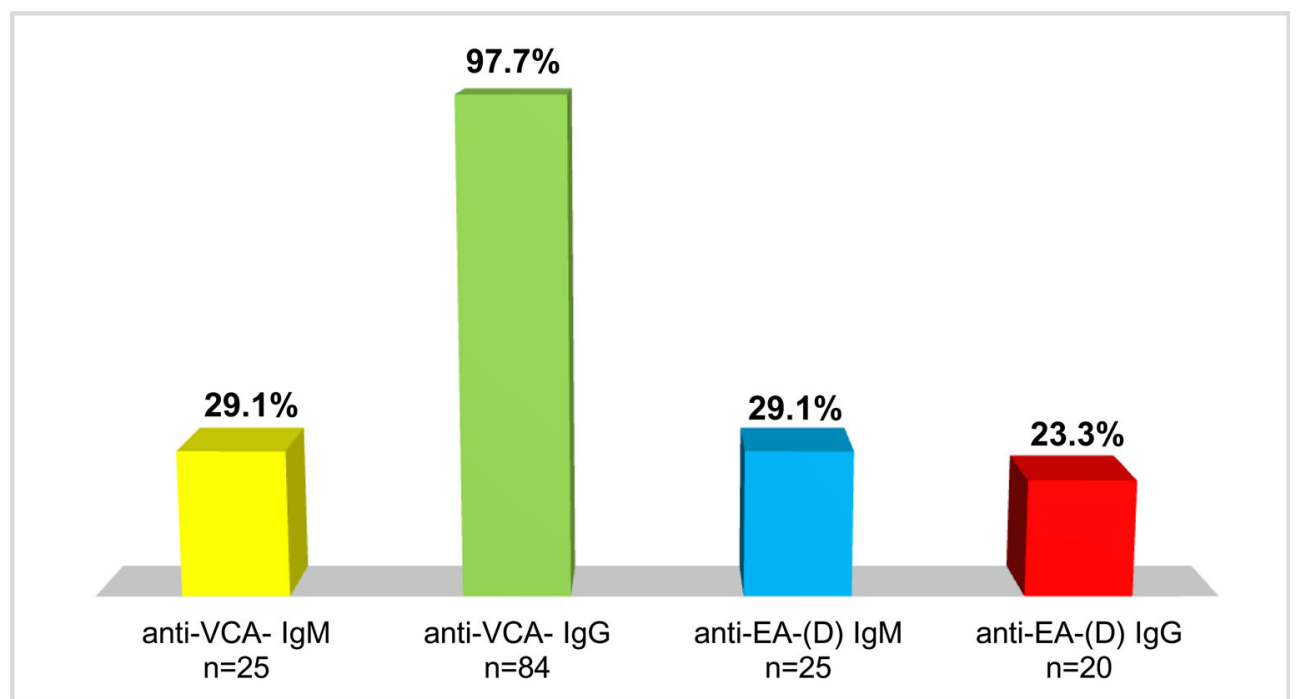

Three of the primary infections $(n=27)$ did not demonstrate anti-VCA IgM and two - anti-VCA IgG antibodies. Patients positive only in the $\operatorname{IgM}$ test were also positive in the anti-EA (D) IgM test. Patients positive only for anti-VCA IgG test did not show anti- EA (D) (Table 1).

Table 1. Antibodies combination found in the studied patients

\begin{tabular}{|l|c|c|c|}
\hline \multicolumn{1}{|c|}{ Diagnosis } & IM & Lymphomas & IS \\
Combination Ab & 15 & 0 & 0 \\
\hline $\begin{array}{l}\text { anti VCA IgM/IgG } \\
\text { anti EA(D)IgM/IgG }\end{array}$ & 0 & 2 & 2 \\
\hline $\begin{array}{l}\text { anti VCA IgG, } \\
\text { anti EA(D)IgM }\end{array}$ & 0 & 1 & 4 \\
\hline $\begin{array}{l}\text { anti VCA IgG, } \\
\text { anti EA(D)IgG }\end{array}$ & 2 & 0 & 0 \\
\hline $\begin{array}{l}\text { anti VCA IgM, } \\
\text { anti EA(D)IgM }\end{array}$ & 4 & 0 & 0 \\
\hline $\begin{array}{l}\text { anti VCA IgM/IgG } \\
\text { anti EA(D)IgM }\end{array}$ & 3 & 1 & 0 \\
\hline $\begin{array}{l}\text { anti VCA IgM, } \\
\text { anti VCA IgG }\end{array}$ & 3 & 24 & 25 \\
\hline anti VCA IgG
\end{tabular}

\section{DISCUSSION}

Patients were simultaneously tested for the presence of anti-VCA $\operatorname{IgM} / \operatorname{IgG}$ and anti-EA (D) $\mathrm{IgM} / \mathrm{IgG}$. In the case of individuals with primary infection (IM), the proportion of the positivity was high for both markers of the EA (D) $(77.8 \%$ in anti-EA (D) $\operatorname{IgM}$ and $55.6 \%$ in $\operatorname{IgG}$ $(\mathrm{p}>0.05))$ as expected. All anti-EA (D) IgG positive patients were also positive for anti-EA (D) IgM. Various data on the frequency of evidence of anti-EA (D) IgG exist in the literature. According to one study, the relative propor- tion of anti-EA (D) IgG was higher - $85 \%$, compared to that in our study [1]. In another study, the proportion of positive patients with primary infection (anti-VCA IgM/ IgG positive) was found to be similar to our result (57\%). The authors demonstrated a higher proportion of anti-EA (D) $\mathrm{IgG}$ positive samples in patients with primary infection and detectable anti-VCA $\operatorname{IgG}(60 \%)$ and in patients with previous infection (without anti-EBNA 1) in 67\% [4]. We have not found studies to determine the role of $\operatorname{IgM}$ antibodies against EA (D) in patients with IM, but our data suggest that in primary infection they are more informative than IgG antibodies and are found in the majority of cases. The proportion of anti-VCA IgM and anti-EA (D) IgM were different, respectively $88.9 \%$ (95\% CI: $70.8 \%$ $97.6 \%, \mathrm{n}=24)$ for anti-VCA $\operatorname{IgM}$ and $77.8 \%(95 \% \mathrm{CI}$ : $55.7 \%-91.4 \%, \mathrm{n}=21$ ) for anti-EA (D) $\operatorname{IgM}$. This is in accordance with the fact that antibodies against EA (D) are not detected in all cases of primary infection. We found that two of the patients with primary infection were positive onlyfor anti- VCA IgM and had anti-EA (D) IgM. According to De Paschale M., (2012), the use of the antiEA (D) proof tests can confirm primary infection in the case of isolated anti-VCA IgM or IgG models [1]. In our study, individuals with detectable IgG only against VCA had no antibodies against EA- (D).

When interpreting the results of patients with different types of lymphoma and other IS, the key question is whether the detection of anti-EA (D) IgM and anti-EA (D) IgG can be considered significant for viral reactivation. It was found that in patients with HL there was an increase in antibody titers to VCA and EA compared to a control group. The modified serological profile even precedes the disease for several years and may serve as a prognostic factor according to the literature [5].

All lymphoma and IS patients were positive in the anti-VCA IgG, indicating infection with the virus. Consideringthe presence of anti-EA (D) IgM or IgG, the viral infection may be reactivated at $15.3 \%$ (95\% CI: $7.2 \%$ $27.0 \%$ ) in both groups of patients. In patients with a pre- 
vious infection (anti-VCA $\operatorname{IgM} / \operatorname{IgG}$ positive, anti EBNA $1 \mathrm{IgG}$ positive), Chan K. et al. (2001) found $50 \%$ positivity in anti-EA (D) IgG and only one detectable EBV DNA. Some authors accept anti-EA (D) seroconversion or quantitative determination in two serum samples as a better possibility for reactivation [6]. According to our data, given the AI values in the anti-EA (D) $\operatorname{IgM}$ and $\mathrm{RU} / \mathrm{ml}$ assay in the anti-EA (D) IgG test, in two IS patients, we found a high $\mathrm{AI}>5$ times the reference values. In positive patients with lymphomas, the values for both markers were closer to the threshold of the test. In the literature, serological methods using anti-EA (D) IgA in patients with proven high levels of anti-VCA IgG have prognostic value for NPC development but, in all other EBV associated tumors, they are not considered determinant. In these cases, the detection of EBV DNA is essential [7].
In conclusion, this study is the first time to our knowledge when the detection of antibodies against EA (D) alone and/or in combination with antibodies against VCA is performed in our country. On the basis of the analysis we can draw the following conclusions:

1. Diagnostic tests used for routine diagnosis of antibodies to VCA have a much better diagnostic value in defining primary infection, serology screening, and EBV associated diagnosis patients compared to EA- (D) antibodies.

2. In our opinion, the use of antibodies against EA(D) in the case of isolated anti-VCA IgM and anti-VCA IgG needs further evaluation.

3. Use of anti-EA (D) IgG as a reactivation marker should be compared with Real-time PCR results for EBV DNA presence.

\section{REFERENCES:}

1. De Paschale M, Clerici P. Serological diagnosis of Epstein-Barr virus infection: Problems and solutions. World J Virol. 2012 Feb 12; 1(1):3143. [PubMed] [Crossref]

2. Klutts JS, Ford BA, Perez NR, Gronowski AM. Evidence-based approach for interpretation of EpsteinBarr virus serological patterns. J Clin Microbiol, 2009 Oct;47(10):3204-10. [PubMed] Crossref]

3. Hess RD. Routine Epstein-Barr Virus Diagnostics from the Laboratory
Perspective: Still Challenging after 35 Years. J Clin Microbiol. 2004 Aug; 42(8): 3381-3387.

4. Chan $\mathrm{KH}, \mathrm{Ng} \mathrm{MH}$, Seto WH, Peiris JSM. Epstein-Barr Virus (EBV) DNA in Sera of Patients with Primary EBV Infection. J Clin Microbiol. 2001 Nov; 39 (11): 4152-4154. [Crossref]

5. Levin LI, Chang ET, Ambinder RF, Lennette ET, Rubertone MV, Mann $\mathrm{RB}$, et al. Atypical prediagnosis Epstein -Barr virus serology restricted to EBVpositive Hodgkin lymphoma. Blood.
2012 Nov;120(18):3750-5. [PubMed] [Crossref]

6. Obel N, Hoier-Madsen M, Kangro $\mathrm{H}$. Serological and clinical findings in patients with serological evidence of reactivated Epstein-Barr virus infection. APMIS. 1996 Jun;104(6):424-8. [PubMed]

7. Gulley ML, Tang W. Laboratory assays for Epstein-Barr virus-related disease. J Mol Diagn. 2008 Jul;10(4): 279-92. [PubMed] [Crossref]

Please cite this article as: Kostadinova T, Ivanova L, Todorova T, Stoykova Z, Tsaneva D, Tsankova G. Role of anti-EA(D) IgM and anti-EA-(D) IgG tests in patients with primary EBV infection, lymphomas and immunosuppression. $J$ of IMAB. 2018 Oct-Dec;24(4):2267-2271. DOI: https://doi.org/10.5272/jimab.2018244.2267

\section{Address for correspondence:}

Tsvetelina Kostudinova Popova

Education and Research Sectors of Medical Laboratory Assistant, Medical College, Medical University- Varna

84, Tsar Osvoboditel Blvd., Varna, Bulgaria.

E-mail: ckostadinova@abv.bg

https://www.journal-imab-bg.org 